\title{
A ESTRUTURA E AS FERRAMENTAS DA INTERVENÇÃO-PESQUISA SÓCIO-ECONÔMICA NAS EMPRESAS E DEMAIS ORGANIZAÇÕES
}

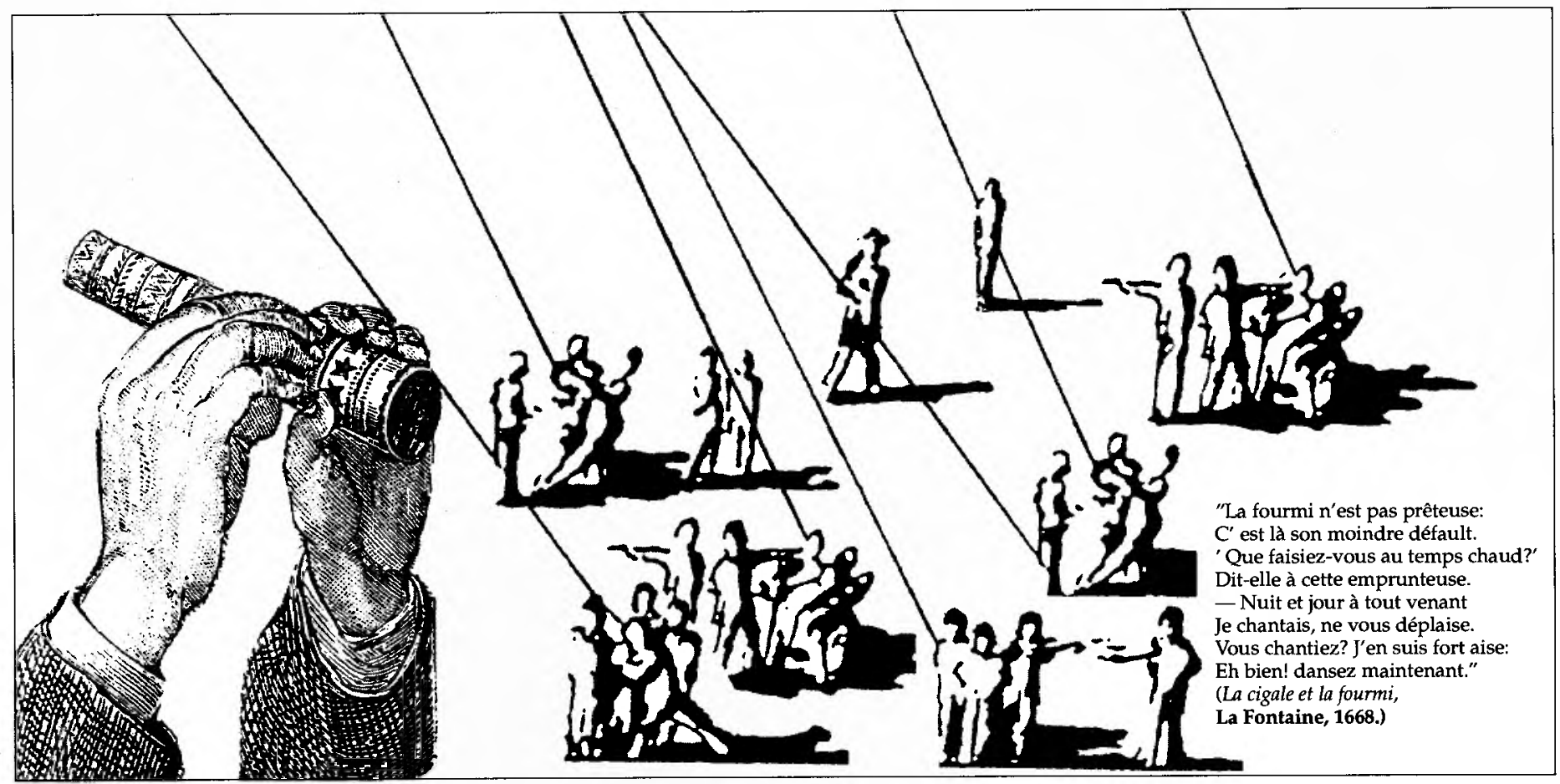

- Marcelo Alceu Amoroso Lima

Professor da Universidade Federal de São Carlos e pesquisador visitante do Instituto de Sócio-Economia das Empresas e das Organizações (ISEOR), França.

* RESUMO: O método de intervenção-pesquisa nas empresas e organizações baseia-se em uma técnica de extração simultânea de informações de ordem econômica $e$ social com o objetivo de compreensão científica e de intervenção na realidade organizacional.

As experiências de pesquisa-intervenção já realizadas permitiram a construção de uma teoria particular sobre o funcionamento das empresas e organizações $e$ o desenvolvimento de "ferramentas" de gestão capazes de auxiliar a melhoria de sua eficiência social e econômica.

A possibilidade de adaptação do método à realidade brasileira baseia-se na relevância dos resultados já alcançados e na sua flexibilidade de aplicação.

* PALAVRAS-CHAVE: Teoria sócio-econômica das em- presas e organizações, custos ocultos, pesquisa-intervenção, pesquisa-ação, metodologia de pesquisa em administração.

* ABSTRACT: The method of research-intervention in the firms and organizations is based on a technique of simultaneous extraction of social and economic information with the purpose of scientific understanding and intervention in the organizational reality. The experiences of research-intervention already realized have permitted the construction of a particular theory of the firm and of the organization and the development of management tools for the improvement of their social and economic efficiency.

The importance of the adaptation of the method to the Brazilian reality is based on the relevance of the results already attained and on its flexibility of application.

* KEY WORDS: Socio-economic theory of the firm and of the organization, hidden costs, research-intervention, research-action, management research methodology. 
1. SAVALL, H. Enrichir le travail humain dans les entreprises et les organisations. (Prefácio de Jacques Delors. Dunod, 1975, 213 págs. Menção especial do prêmio "I.A.E. Management", Paris, 1976. Traducão espanhola: Por un trabajo mas humano, Madrid, Ed. Techniban, 1977; tradução inglesa: Work and people (prefácio de H.I.Ansoff), Oxford University Press, 1981; 2a. edição aumentada: Enrichir le travail humain: l'evaluation économique, Dunod, 1978 (3a. tiragem 1979).

2. SAVALL, H. Reconstruire l'entreprise. Analyse socioéconomique des conditions de travail. (Prefácio de Franccois Perroux.) Dunod, 1979, 275 págs.

3. Pontos desenvolvidos nos seminários metodológicos da pós-graduação em gestão sócio-econômica de 1988/1989, proferidos pelo professor H. Savall.

4. Ver SAVALL, H. \& ZARDET, V. Maîtriser les coûts cachés. Le contrat d'activité périodiquement négociable. (Prefácio de M.A. Lanselle e Introdução de J.M.Doublet.) Colleção Gestão, Ed. Econômica, abril, 1987, 334 págs.; e SAVALL, $H$. "Mettre en évidence les coûts cachés". In: revista Courrier du CNRS Dossier "Une jeune discipline au CNRS: la recherche en gestion", n 64 , jan-mar., 1986, 4 págs.

\section{INTRODUÇÃO}

A concepção sócio-econômica em administração é, simultaneamente, uma abor1 dagem de política geral, uma metodologia de pesquisa, e um método de intervenção nas empresas e nas organizações.

Essa concepção foi desenvolvida inicialmente por Henri Savall nos livros Enrichir le travail humain dans les entreprises et les organisations ${ }^{1}$ e Reconstruire l' entreprise: Analyse Socio-économique des conditions de travail ${ }^{2}$, que propõe uma nova concepção e operacionalização em administração, denominada gestão sócio-econômica.

Após 1976, a análise sócio-econômica tem sido praticada e aperfeiçoada através das pesquisas do Instituto de Sócio-Economia das Empresas e das Organizações (ISEOR), sob a direção de H. Savall, em várias intervenções.

\section{A ESTRUTURAÇÃO dO MÉTODO SÓCIO-ECONÔMICO}

Enquanto o pensamento tradicional em ciências da administração permanece em geral vinculado à aparência dos fenômenos, na medida em que não é construído a partir do funcionamento real das empresas e organizações, a análise sócio-econômica procura encontrar a essência dos fenômenos pela vivência dos problemas organizacionais e pela teorização de soluções através da metodologia da intervenção-pesquisa ${ }^{3}$.

Os conceitos da metodologia sócio-econômica estruturam-se em três dimensões:

- A dimensão das decisões políticas, que contempla a estratégia empresarial, as regras do jogo explicitadas aos atores das empresas e organizações que servirão de terreno experimental, a definição dos parâmetros dos con- tratos de atividade periodicamente negociáveis e a política social.

- A dimensão das ferramentas de trabalho, que contempla o contrato de atividades periodicamente negociável (CAPN), o painel de pilotagem sócio-econômica, a matriz de competências, a matriz de auto-análise da gestão do tempo e o plano de ações prioritárias.

- A dimensão do processo de intervenção-pesquisa sócio-econômico, que contempla o diagnóstico, o projeto de melhoramento, a operacionalização do projeto e sua avaliação.

Apresentam-se, a seguir, a definição e articulação dos principais conceitos da análise sócio-econômica, no que tange às duas primeiras dimensões.

\section{A INTERAÇÃO ESTRUTURA-COMPORTAMENTO COMO HIPÓTESE CENTRAL DO FUNCIONAMENTO DA EMPRESA}

A estrutura da organização é definida como o conjunto de elementos relativamente permanentes que se caracterizam pela capacidade de duração no tempo de seus principais atributos, pela sua capacidade de evolução autônoma, lenta e progressiva e pelo alto nível de dispêndio de energia social (individual ou coletiva), mais ou menos concreta, material e financeira, necessária à realização de uma evolução mais rápida.

As estruturas de uma organização apresentam duas características principais:

- um certo grau de inércia (não somente com relação aos atores, mas também com relação ao tempo);

- uma capacidade de impressionar os comportamentos humanos (propriedade de prenhez) 4 .

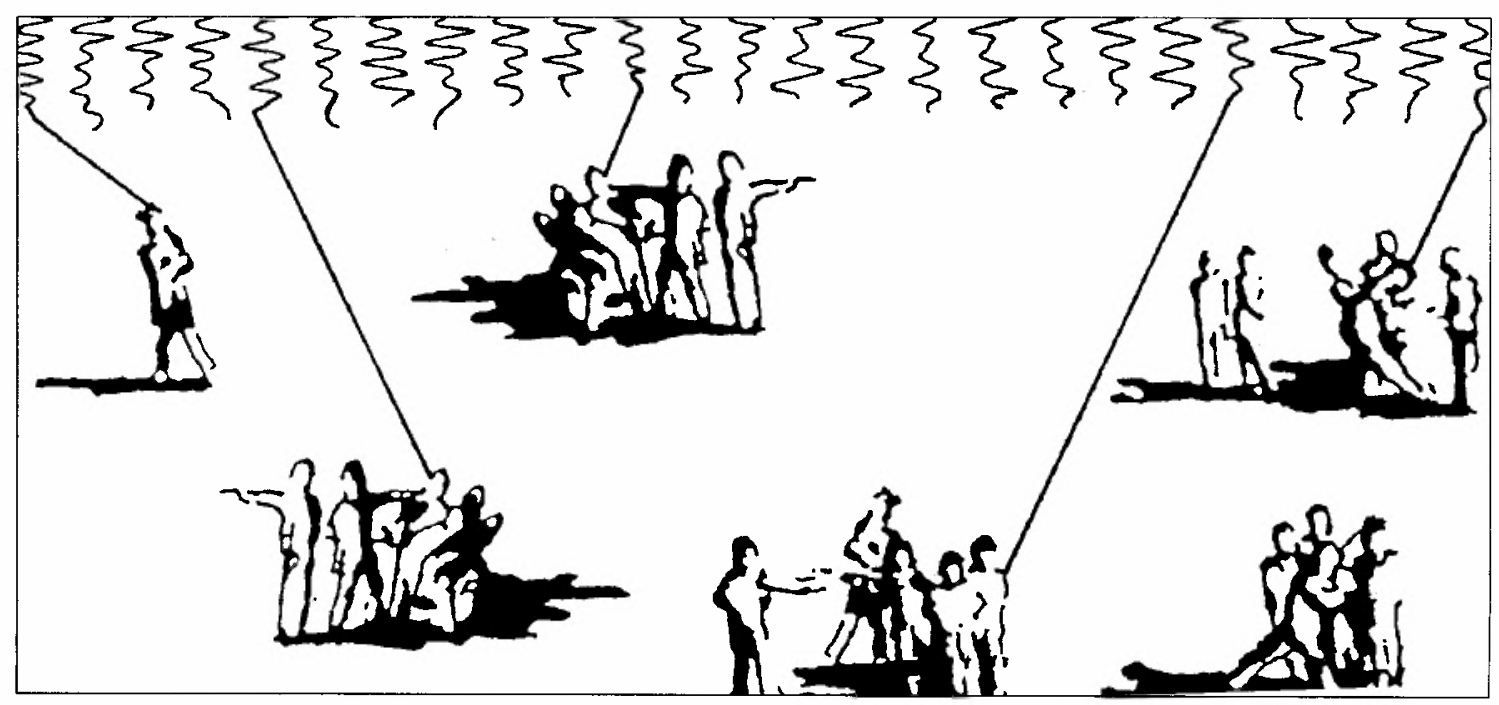


O conjunto de elementos da organização que apresenta as duas propriedades de inércia e de prenhez pode ser reagrupado em cinco categorias de estruturas: física, tecnológica, organizacional, demográfica e mental, conforme se vê no quadro 1.

Os comportamentos, por sua parte, "... são definidos como as manifestaçóes do homem, efetivamente observadas, $e$ que tên uma incidência sobre o ambiente físico e social"

Hles se caracterizam por sua natureza conjuntural e sua relativa instabilidade.

As lógicas de comportamento, de acordo com as situaçóes e a natureza dos problemas que se apresentam ao individuo, podem ser classificadas como lógica individual (personalidade e as características profissionais e ex- tra-profissionais, principalmente familiares), lógica de grupo de atividade (pertinência a um determinado serviço), lógica da categoria (pertinĉncia a uma categoria profissional) lógica de grupo de pressão (pertinência a uma convicção moral, religiosa, política, sindical, de origem comum), lógica coletiva (por exemplo, nas situaçōes em que se coloca em risco a existência mesmo da cmpresa).

Essas lógicas resultam de quatro fatores principais: das características do individuo, das características estruturais do ambiente (profissional e extra-profissional) do indivíduo, da cronobiologia pessoal do indivíduo (no sentido dos ritmos biológicos do sistema humano de acordo com os períodos do dia, do mês c do ano), dos fenômenos conjuntu-

Quadro 1: Categorias e principais elementos da estrutura de uma organização

\begin{tabular}{|c|c|c|c|c|}
\hline $\begin{array}{c}\text { Estrutura } \\
\text { Física }\end{array}$ & $\begin{array}{l}\text { Estrutura } \\
\text { Tecnalógica }\end{array}$ & $\begin{array}{c}\text { Estrutura } \\
\text { Organizacional }\end{array}$ & $\begin{array}{c}\text { Estrutura } \\
\text { Demográfica }\end{array}$ & $\begin{array}{c}\text { Estrutura } \\
\text { Mental }\end{array}$ \\
\hline $\begin{array}{l}\text { E espaço físico } \\
\text { configuração } \\
\text { dos locais } \\
\text { de trabalho } \\
\text { condiçôes } \\
\text { de trabalho } \\
\text { - ruido } \\
\text { - calor } \\
\text { - toxicidade } \\
\text { - luminosidade }\end{array}$ & $\begin{array}{l}\text { qrau de } \\
\text { desgaste e } \\
\text { de uso dos } \\
\text { equipamentos } \\
\text { - sofisticação. } \\
\text { complexidade } \\
\text { e grau de } \\
\text { automatizacãa } \\
\text { adaptabilidade } \\
\text { dos equipamentos } \\
\text { às necessidades } \\
\text { da atividade } \\
\\
\text { incidências } \\
\text { sobre a } \\
\text { adequação- } \\
\text { formação-emprego } \\
\\
\text { condições de } \\
\text { trabalho ligadas } \\
\text { aos materiais }\end{array}$ & $\begin{array}{l}\text { - organograma } \\
\text { - sociograma } \\
\text { - divisäo do } \\
\text { trabaho } \\
\text { - métodos } \\
\text { operacionais } \\
\text { - horários } \\
\text { e ritmos de } \\
\text { trabalho } \\
\text { - procedimentos } \\
\text { - sistemas de } \\
\text { comunicação- } \\
\text { coordenação- } \\
\text { concertamento } \\
\text { - sistema } \\
\text { de informação } \\
\text { funcional e } \\
\text { operacional }\end{array}$ & $\begin{array}{l}\text { ajustamento } \\
\text { dos efetivos } \\
\text { Dirâmide etária } \\
\text { e estrutura da } \\
\text { população } \\
\text { - instâncias } \\
\text { de representação } \\
\text { e concertamento } \\
\text { - mão-de-obra } \\
\text { disponível na } \\
\text { região } \\
\text { - estruturação } \\
\text { das formaçôes } \\
\text { iniciais } \\
\text { - formação } \\
\text { contínua } \\
\text { - estruturas } \\
\text { das qualificações } \\
\text { carreiras } \\
\text { profissionais e } \\
\text { promocionais } \\
\text { a políticas de } \\
\text { recrutamento }\end{array}$ & $\begin{array}{l}\text { - estilo de } \\
\text { gestão } \\
\text { - "espírito da casa" } \\
\text { (cultura da } \\
\text { organização) } \\
\text { - microclimas } \\
\text { - concepções } \\
\text { sócio-culturais } \\
\text { dominantes } \\
\text { (ideologias } \\
\text { profissionais) }\end{array}$ \\
\hline
\end{tabular}

Obs.: a matriz não é exaustiva e pode ser adaptada de acordo com a organização.

Fonte: SAVALL, H. \& ZARDET, V. Op. cit., p. 43.

5. SAVALL. H. \& ZARDET, V Op. cit., p. 145.

6. Idem, ibidem, idem. 
rais do meio-ambiente.

A interação das estruturas com os comportamentos dá origem a disfunçōes que redundam em custos ocultos, que traduzem uma perfomance atrofiada da cmpresa, conforme esquematizado na figura 1.

Conforme salientado nessa figura, a empresa ou organização é considerada como um conjunto complexo de estruturas de cinco tipos (físicas, tecnológicas, organizacionais, demográficas e mentais) em interação com cinco tipos de comportamento humano (individuais, de grupo de atividade, de categoria, de grupo de pressão e coletivos). Essa interação permanente e complexa cria as pulsaçôes de atividade que constituem o seu funcionamento.

Pode-se discernir nesse funcionamento um diferencial entre funcionamento desejado e funcionamento observado; esse diferencial corresponde às disfunções, classificadas $\mathrm{cm}$ seis famílias: condiçōes de trabalho, organização do trabalho, comunicação-coordenaçãoconcertamento, gestão do tempo, formação integrada e operacionalização da estratégia.

Essas seis famílias constitucm, ao mesmo tempo, as variáveis explicativas e os domínios de solução das disfunçōes recenseadas.

As disfunçôes dão origem a custos, em geral ocultos, que são computados através da mensuração do impacto econômico associado aos fenomenos de absenteísmo, acidentes de trabalho, rotação do pessoal, qualidade dos produtos e produtividade direta.

$\Lambda$ situação normal das empresas é ter uma hipertrofia de disfunçoes e de custos ocultos, $\mathrm{em}$ função de uma atrofia dos comportamentos, das estruturas e dos sistemas de informação operacionais e funcionais humana-

Figura 1: A busca dos Custos Dcultos

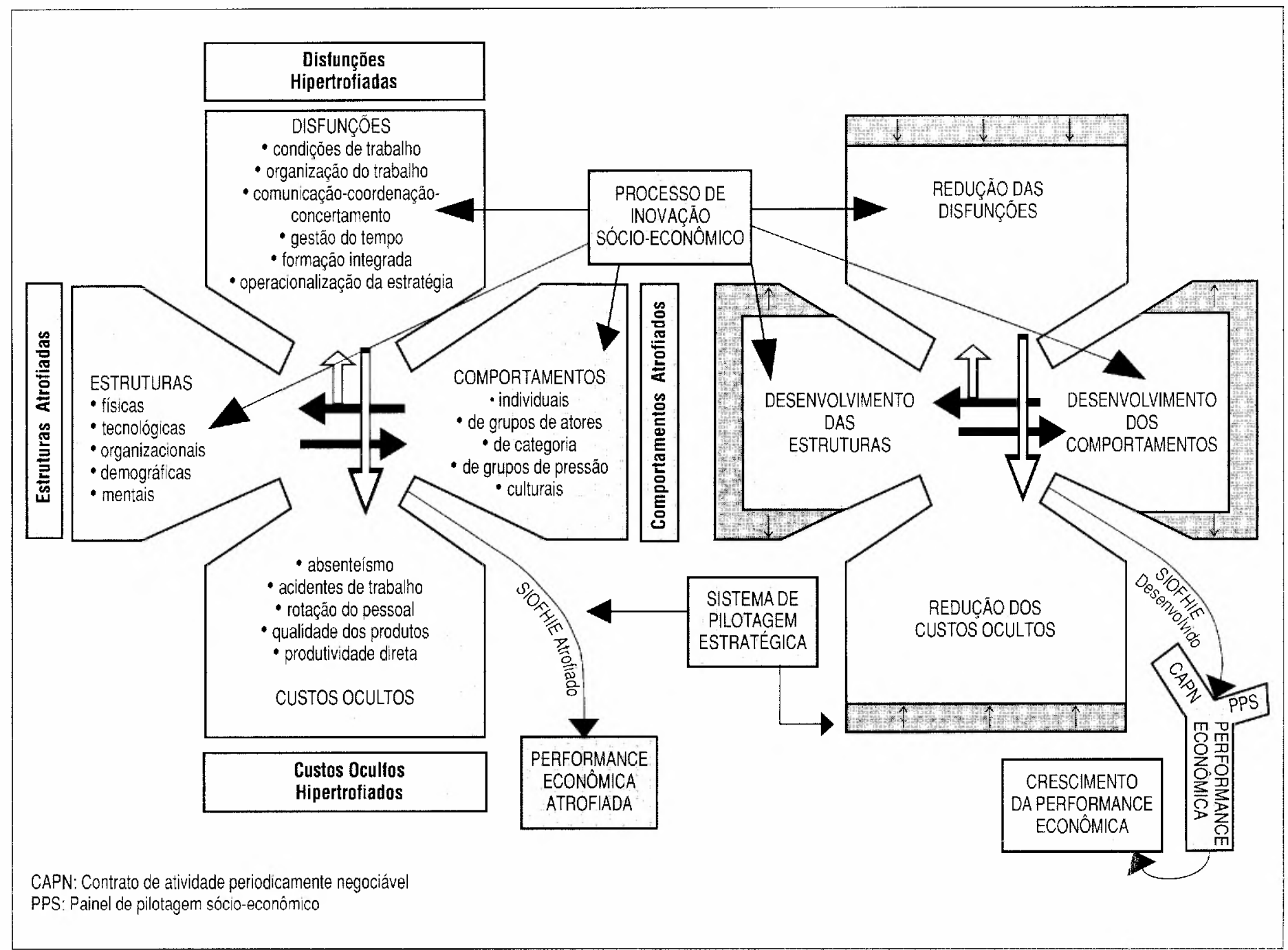

Fonie: SAVALL, H. \& ZARDET, V. Op. cit., p. 182. 
mente integrados e estimulantes (SIOFHIE).

A intervenção sócio-econômica é proposta, conseqüentemente, de forma a desenvolver os comportamentos, as estruturas e os sistemas de informação operacional e funcional humanamente integrados e estimulantes, com o objetivo de reduzir as disfunções e custos ocultos.

\section{A ANÁLISE DOS CUSTOS OCULTOS}

Disfunção é, portanto, o ponto que, por convenção, vai ser assinalado como o diferencial entre o funcionamento esperado e o funcionamento atingido e que está na origem de um conjunto de custos ocultos.

Regulação é o conjunto de atos que vão ser feitos pela empresa para resolver a disfunção (regulação da disfunção) e, em um segundo nível, para reduzir (e eventualmente suprimir) as disfunções no futuro (regulação de equilibração).

As disfunções geram custos para a empresa que são em geral ocultos e que afetam sua performance econômica.

Os custos ocultos compreendem quatro componentes principais? ${ }^{7}$. Os três primeiros constituem dispêndios que a empresa poderia evitar, ao menos parcialmente, se seu nível de disfunção fosse menos elevado: trata-se dos sobre-salários (ou salários de indenização) versados sem contrapartida em trabalho (em alguns casos de ausência do pessoal, por exemplo), dos tempos de regulação (remuneração do tempo dedicado a corrigir as disfunções ao invés de efetuar uma produção faturável) ou aỉnda de sobreconsumo (consumo de energia, de material ou de suprimentos externos cujo nível seria inferior se a empresa tivesse menos disfunções a corrigir). O quarto componente dos custos ocultos é de natureza particular, pois não constitui propriamente uma carga mas, sobretudo, um não produto ou uma perda de receitas de produção. Trata-se das ocasiões perdidas com relação a realizar e vender um produto (custos de oportunidade).

A razão pela qual as empresas raramente medem e verificam os custos ocultos é que estes se encontram esfacelados e disseminados. É o recolhimento desses microcustos que resulta em montantes exorbitantes e não uma localização precisa nesta ou naquela parte da empresa. Por outro lado, os custos ocultos não fazem parte dos procedimentos de engajamento financeiro, como é o caso dos custos ditos visíveis.

Os custos ocultos constituem-se, portanto, de sobrecargas (sobre-salário, sobretempo e sobreconsumo) e de não produtos (não produção e não criação de potencial estratégico).

Essas sobrecargas e esses não produtos são identificados por rubricas de indicadores: absenteísmo, acidentes de trabalho, rotação do pessoal, qualidade dos produtos (bens e serviços) e produtividade direta.

Os elementos de custo de absenteísmo podem ser classificados em: tempo passado pelos supervisores, pela liberação da produção e pelos operários na realocação das tarefas; não produção; defeitos eventuais de qualidade; sobrecustos salariais (horas suplementares, pessoal adicional); não cobertura dos custos fixos da estrutura; subprodutividade dos operários substituintes.

Os elementos de custo de acidente de trabalho podem ser classificados da seguinte forma: custos diretos; salário de ausente substituído; tempo passado pelos supervisores na regulação da perturbação; não produção (parada das máquinas); perturbação do ambiente de trabalho; primeiros socorros. Se o acidente for cobrado adicionalmente pela previdência social: aumento da cotização da empresa à previdência social; procedimentos administrativos de declaração à previdência social.

Os elementos de custo de rotação do pessoal podem ser classificados da seguinte forma: complemento da amortização do investimento em recursos humanos realizado sobre os operários que partem; custo de recrutamento; custo da formação; procedimentos de partida; perturbações da atividade; investimento em recursos humanos efetuados sobre o substituinte . $^{8}$.

O custo de não qualidade ${ }^{9}$ pode ser decomposto da seguinte forma: custo comercial da devolução e da troca do lote defeituoso (custo do tempo passado a resolver o litígio em lugar de realizar uma nova venda - tempo de regulação mais tempo de não produção); custo de produção dos retoques, das reciclagens, de disposição dos refugos (custo do tempo passado a efetuar os retoques, consumo de material e de energia nesse sentido, perda de produção durante o tempo que se passa a resolver esses litígios ao invés de produzir um novo lote faturável - tempo de regulação mais sobreconsumo mais não produção).

Os custos ocultos ligados à produtividade direta $^{10}$ são decompostos da seguinte forma: sobreconsumo de matérias-primas e de material secundário, não produção representada por uma diferença a ganhar ligada seja às paradas de máquina, seja a uma menor produtividade do trabalho humano (habilidade, rapidez), seja a problemas de aprovisionamento e de ritmo entre postos de trabalho. As seis famílias interativas de variáveis explicativas e de domínio de solução das disfunções, que dão origem aos custos ocul-
7. Idem, ibidem, cap. 3 .

B. Ver MEILHAUD, J. \& LANDRY, P. "Productivité Les hommes font la différence". Revista L'Usine Nouvelle, setembro, 1985, 4 págs.

9. Pontos desenvolvidos sobretudo em SAVALL, $H$ "Stratégie socio-économique des entreprises". In: Rapport de la Comission Industrie, La Documentation Francaise, julho, 1980, pp. 223-31. Anexo do relatório do grupo "Condiç̃os de Trabalho e Estratégla Industrial" (trabalhos preparatórios do VIII Plano Qüinqüenal Francês); Comissariado Geral do Plano.

10. Ver SAVALL, H. \& ZARDET, V. Op. cit., cap. 3. 
Figura 2: Variáveis Explicativas das Disfunções

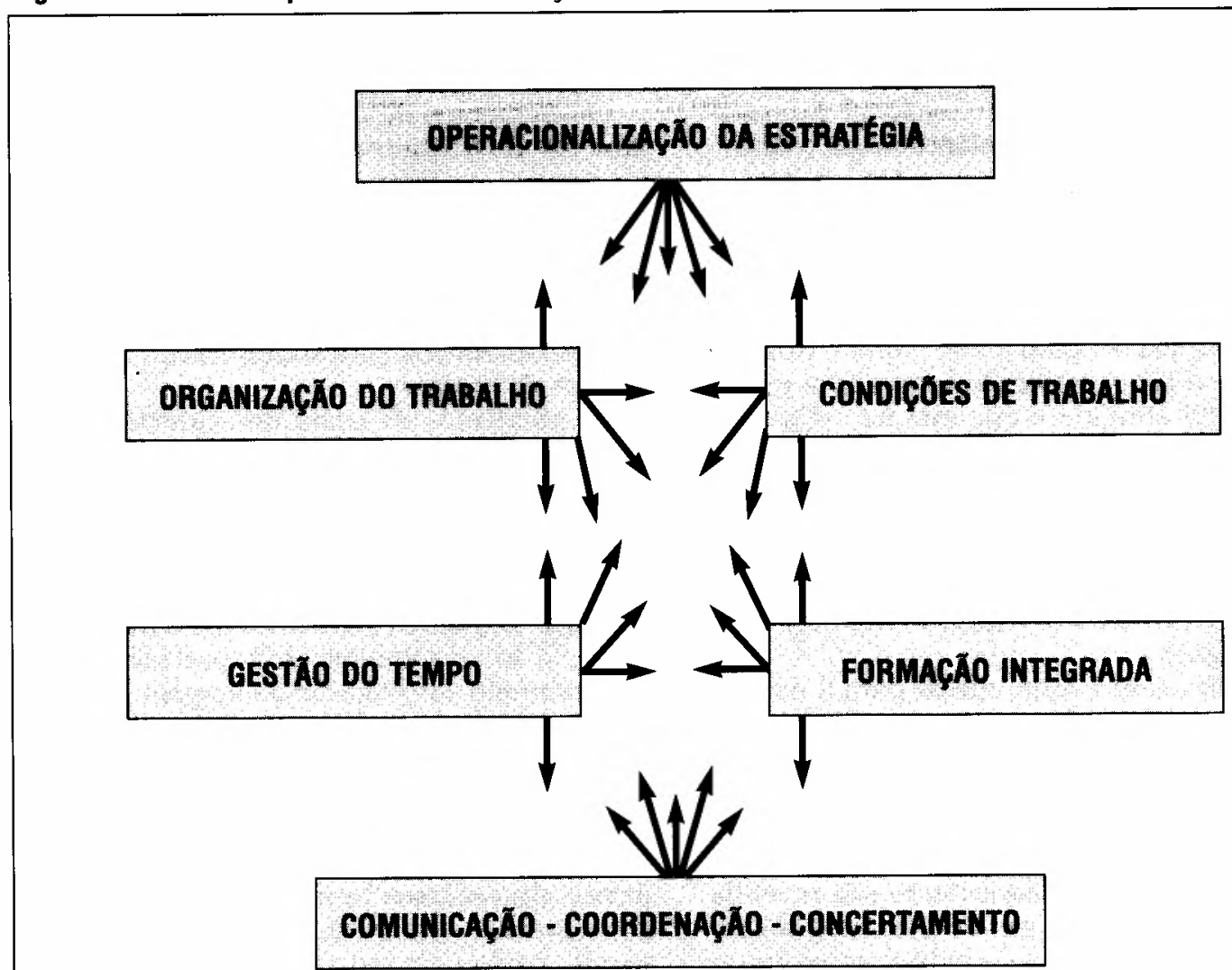

11. Ver SAVALL, $H$. "Les coûts sociaux: importance économique des coûts cachés liés à l'absenteisme, la rotation du personnel, la qualité et la production directe". Revue de l' Ecole des Mines de Sainte-Etienne, abril 1983, 6 págs., apud SAVALL, H. \& ZARDET, V. Op. cit.

12. Ver SAVALL, H. \& ZARDET, V. Op. cit., cap. 5.

Fonte: SAVALL, H. "Les coûts sociaux: importance économique des coûts cachés liés à l'absenteisme, la rotation du personnel, la qualité et la production directe". Op. cit.

tos, são esquematizadas na figura $2^{11}$.

Essas famílias de variáveis explicativas podem ser detalhadas da seguinte forma ${ }^{12}$ :

- Operacionalização da estratégia: corresponde às técnicas, aos métodos e às práticas de transformação, de declinação e de tradução dos objetivos estratégicos da empresa em ações concretas para atingi-los.

- Condições de trabalho: reagrupa as condições físicas e as relações de trabalho.

- Organização do trabalho: repartição das funções internas da empresa, organização dos postos individuais de trabalho dentro de cada unidade, interdependência dos postos de trabalho e das atividades.

- Gestão do tempo: métodos de organização do tempo de trabalho individual e coletivo, repartição do tempo do indivíduo entre suas grandes atividades (preparação-execução-controle, prevenção-regulação, funcionamento corrente, desenvolvimento...).

Uma boa gestão do tempo é prioritária para permitir a realocação do tempo para a pi- lotagem estratégica, para a realização de tarefas anteriormente mal assumidas e para a prevenção dos disfuncionamentos, em detrimento do tempo passado com a regulação de disfuncionamentos, com a execução de funções de subordinados ou de "tarefas-parasitas."

A propósito da alocação do tempo produtivo, a estratégia sócio-econômica sugere duas idéias básicas:

Em primeiro lugar, a cada função da tradicional pirâmide de ocupações, deve corresponder também uma taxa de tempo indiretamente produtivo, isso sendo mais produtivo e criando menos perturbação do que uma especialização excessiva das pessoas em tarefas diretamente produtivas para alguns e indiretamente produtivas para outros. Essa taxa deve ser, entretanto, crescente proporcionalmente ao grau hierárquico de cada um. O tempo indiretamente produtivo constitui a alocação necessária para que cada um, de acordo com as características de seu posto de trabalho, possa se informar, comunicar, preparar e par- 
ticipar do processo complexo de atividades da empresa.

Em segundo lugar, a razão "tempo diretamente produtivo/tempo indiretamente produtivo" deve ser seguida como um indicador estratégico de primeira ordem. Esse elemento da estratégia indica a importância da gestão dos orçamentos de tempo de todas as categorias de pessoal ${ }^{13}$.

A família "formação integrada" corresponde às práticas de formação profissional e de adequação formação-emprego dentro de uma ótica de integração do conhecimento (savoir) com a prática (faire).

Com relação à família (comunicação-coordenação-concertamento), ela é compreendida da seguinte forma:

“... uma articulação operacional e funcional entre os indivíduos para a realização de suas atividades.

A comunicação reagrupa todos os tipos de troca de informações entre atores: formais ou informais, hierárquicas ou horizontais, relativas ou não à atividade profissional.

A coordenação aplica-se aos dispositivos de troca de informação entre atores, organizados tendo em vista a realização de objetivo funcional ou operacional da atividade.

O concertamento caracteriza os tipos de troca de informação entre atores que permite definir um objetivo operacional ou funcional comum a realizar em um período determinado" ${ }^{14}$.

Uma das causas freqüentes de disfunção é não haver uma articulação da informação. Nesse sentido, a análise sócio-econômica propõe a concepção de sistemas funcionais e operacionais humanamente integrados e estimulantes (SIOFHIE).

\section{PRINCIPAIS FERRAMENTAS}

Entre as ferramentas de gestão desenvolvidas pela análise sócio-econômica, as principais são as seguintes:

$\mathrm{O}$ contrato de atividades periodicamente negociável $(\mathrm{CAPN})^{15}$ é um acordo temporário feito entre um assalariado e seu superior hierárquico direto para atingir alguns objetivos prioritários da atividade, determinados a partir do diferencial entre o funcionamento esperado pela organização e o funcionamento real observado do assalariado em questão (disfunção).

Esse contrato visa a modificar a dialética conflito-cooperação no seio da organização, de forma a aumentar a zona de convergência dos atores: direção, supervisão, pessoal de base, representação do pessoal.
O acordo temporário dá-se sobre dois pontos: os objetivos de aumento da eficácia dos indivíduos e as contrapartidas fornecidas pela empresa em termos de meios necessários para atingir esses objetivos (meios materiais, de formação, de organização e de informação) e em termos de complemento de salário por ter atingido os objetivos.

O painel de pilotagem sócio-econômica ${ }^{16}$ corresponde a um fichário que possui indicadores visuais e escritos para reterem e reagruparem as informações em diferentes níveis da organização.

Cada membro da empresa que tenha responsabilidades hierárquicas, que seja, por conseguinte, co-piloto da operacionalização da estratégia empresarial, tem necessidade de um painel de pilotagem adaptado a suas funções e à sua zona de responsabilidades.

A partir dos objetivos estratégicos, são construídos os painéis de pilotagem de cada co-piloto, cada painel sendo composto de indicadores da vocação local, para pilotar-se a unidade através de ações específicas, e da vocação global, destinados a alimentar outros painéis de pilotagem.

A articulação e sincronização dos painéis de controle são feitas através de uma consolidação de resultados no alto da hierarquia e por uma incorporação de sinergias em todos os níveis da empresa.

O painel sócio-econômico de pilotagem estratégica é construído de acordo com três princípios: inserir os objetivos estratégicos; articular os indicadores de resultado imediato e de criação de potencial; utilizar conjuntamente indicadores qualitativos, quantitativos e financeiros.

A matriz de competências ${ }^{17}$ corresponde a um quadro sinóptico no qual se podem visualizar as competências efetivas disponíveis de um grupo de pessoas. É também um indicador de criação de potencial dentro do painel de pilotagem.

Os objetivos da matriz de competências são três: melhoramento da adequação formação-emprego; observação dos dois principais critérios da qualidade e da eficácia coletiva de um serviço: as operações vulneráveis (falta de competências disponíveis) e dosagem de polivalência (a especialização de cada pessoa é fonte de seu interesse no trabalho); detecção das necessidades de formação efetivas de cada assalariado (um plano de formação personalizado de cada unidade).

A matriz de auto-análise da gestão do tempo $^{18}$ é uma ferramenta de gestão criada para identificar as tarefas realizadas pelo pessoal durante a jornada de trabalho e as disfunções
13. Idem, ibidem, p. 141.

14. Ver SAVALL, H. "Stratégie socio-économique des entreprises". Op. cit.

15. Ver SAVALL, H. \& ZARDET, V. Op. cit., cap. 1.

16. Idem, ibidem, cap. 2. 17. Idem, ibidem, cap. 4.

18.Ver FRAISSE-SCHEINE$D E R$, Véronique. La grille de gestion du temps de l'analyse socio-économique: un outil d'autodiagnostic au sérvice de l'amélioration du rôle du cadre. Dissertação para a obtenção do "Diplôme d'Etudes Approfondies de Gestion Socio-Economique des Entreprises et des Organisations", apresentada e defendida em 7 de novembro de 1988, na Université Lyon II, 138 págs. 
19. Ver BOGE, Anne. Le Plan d'actions prioritaires: Perspectives d'un outil fondamental de gestion socioéconomique. Evaluation d'un système de gestion décentralisée et synchronisée dans une grande mairie. Dissertacão para a obtencão do "Diplôme d'Etudes Approfondies de Gestion Socio-Economique des Entreprises et des Organisations", apresentada e defendida em 07 de novembro de 1988, na Université Lyon II, 312 págs.

20. Ver SAVALL, H. \& ZARDET, V. (Com a participação de S. LARIVE.) Amélioration de la gestion du temps: outils conceptuels et méthodes opératoires. Cas de l'équipe de direction d'une banque régional. Relatório metodológico ISEOR, junho 1985.

21. Pontos desenvolvidos sobretudo em SAVALL, $H$. "Stratégie socio-économique des entreprises". Op. cit.: SAVALL, H. \& MARTINET, A. "Les axes de la mise en oeuvre de la stratégie projective ouverte". Revue Française de Gestion, jan./fev. 1981; e SAVALL, $H$. \& MARTINET, A. "Stratégie socio-économique de l'entreprise". Revue Francaise de Gestion, mai-jun., 1979, pp.48-58.

22. Ver SAVALL, H. Reconstruire l'entreprise. Analyse socio-économique des conditions de travail. Op. cit.

23. Ver SAVALL, H. \& MARTINET, A. "Les axes de la mise en oeuvre de la stratégie projective ouverte". Op. cit.

24. Ver SAVÁLL, $H$. "Le développement socio-économique de l'entreprise". Revue Française de Gestion, jun-jul-ago, 1985, 11 págs.

25. Idem, ibidem. associadas à natureza das tarefas executadas e à correspondente alocação de tempo. Sua utilização tem por finalidade o melhoramento da gestão do tempo pessoal no sentido da eficácia da empresa.

O plano de ações prioritárias (PAP) corresponde $^{19}$ a uma ferramenta de formulação e gestão das ações a realizar por cada unidade da organização, em um semestre, de forma a atingir os objetivos prioritários definidos a partir das grandes linhas de ação derivadas da estratégia.

Com efeito, o PAP é a fase operacional correspondente à operacionalização dos objetivos estratégicos da organização. A fase conceitual corresponde aos procedimentos que permitem a exposição dos objetivos estratégicos a partir do diagnóstico das disfunções internas e das disfunções com relação ao ambiente externo.

As ações prioritárias para uma operacionalização da estratégia eficaz possuem as seguintes características ${ }^{20}$ :

- uma compreensão generalizada pelos atores da organização;

- uma formulação bem concreta;

- uma planificação em termos do tempo necessário à sua realização.

Cada responsável hierárquico deve, portanto, efetuar dois tipos de trabalho: a definição das ações prioritárias pela declinação das ações prioritárias do nível hierárquico superior e um miniprojeto de redução das disfunções de sua área de responsabilidade e, em segundo lugar, a planificação-programação das ações assim definidas.

\section{A ESTRATÉGIA SÓ́CIO-ECONÓMICA ${ }^{21}$}

A estratégia sócio-econômica apresenta dois elementos-chave articulados: globalidade e sincronização. O que se propõe é o desenvolvimento concomitante da concepção, da formulação e da operacionalização estratégicas.

Na concepção e operacionalização da estratégia, são estudados e supervisionados três elementos capitais: o peso dos fenômenos organizacionais ocultos, ligados às disfunções; a ilusão da externalização dos custos para o ambiente, freqüentemente mal estimados e mal interpretados (transferências de disfunções através da relação fornecedor-cliente); e a questão fundamental da alocação do tempo produtivo.

A estratégia sócio-econômica tem por objetivo definir uma política geral tão coerente quanto possivel, integrando os objetivos-restrições econômicos e sociais. Ela deve permi- tir às empresas desenvolverem sua criatividade em todos os níveis e em todos os domínios, e anteciparem as adaptações estruturais necessárias para enfrentar as mudanças que poderão ocorrer nos planos interno e externo.

A estratégia sócio-econômica corresponde a buscar a transdisciplinaridade, estimular as energias e perseguir a dupla dimensão econômica e social dentro da concepção de que a estratégia de mudança para ser eficaz, durável e penetrante, deve articular estreitamente as alavancas financeiras e as competências sobre as quais se apóia a estratégia dos atores no sentido da sociologia ${ }^{22}$. Há, portanto, na abordagem sócio-econômica, um duplo significado dado à palavra estratégia: no sentido dos economistas, corresponde à ação face ao ambiente econômico, com um componente marketing e com um objetivo de performance financeira; no sentido dos sociólogos, corresponde à estratégia dos atores.

A estratégia sócio-econômica é uma estratégia projetiva aberta, onde se levam em consideração os resultados econômicos imediatos, medidos pela produtividade, pelo autofinanciamento, e pela rentabilidade e os resultados econômicos a médio e longo prazo, ditos de criação de potencial, tais como a criação de novos produtos, de novas técnicas, o melhoramento da competitividade a médio e longo prazo, o melhoramento da qualificação do pessoal, o comportamento de aperfeiçoamento permanente ${ }^{23}$.

O conceito de estratégia sócio-econômica distingue dois tipos de ambiente pertinentes para a estratégia da empresa: o ambiente externo, território do marketing, e o ambiente interno, composto do pessoal da empresa, território habitual da gestão do pessoal, e da gestão da produção. A bem dizer, a estratégia sócio-econômica esforça-se em reunir esses dois ambientes a partir de uma abordagem de marketing estendida ao ambiente interno ${ }^{24}$.

Do ponto de vista do conceito "qualidade", são propostos dois níveis de avaliação: a qualidade externa, julgada pelo consumidor no ambiente externo à empresa, e a qualidade interna, julgada pelos próprios produtores da qualidade no interior da empresa. Esses dois níveis, em geral, não coincidem pois, na maioria dos casos, as empresas só chegam a uma boa qualidade externa às custas de controles e regulações das disfunções extremamente onerosos e, portanto, às custas da qualidade interna ${ }^{25}$.

A estratégia de mudança vista pela sócioeconomia corresponde a integrar a formação do pessoal na estratégia da empresa. É necessário buscar uma estrutura estimulante pela 
construção do consenso. O melhoramento da eficiência global supõe sempre a definição de estruturas de trabalho no sentido de condições e de organização do trabalho adaptadas, ao mesmo tempo, aos projetos da empresa $\mathbf{e}$ aos de seus membros ${ }^{26}$.

A estratégia sócio-econômica é também pensada no sentido eclesiástico, isto é, durável, enraizada, menos vulnerável. Ela deve ser uma estratégia educativa, mais próxima da problemática da evolução da empresa.

Antes que partir de uma análise da demanda solvável e da análise do mercado para deduzir os recursos humanos necessários, 0 caminho da análise sócio-econômica começa por uma análise do potencial da empresa e estimula, a partir deste, a descoberta das estratégias "produto-mercado-tecnologia" economicamente viáveis ${ }^{27}$.

Uma formulação do quadro geral da análise sócio-econômica é proposta em $R e$ construire l'entreprise, da seguinte forma:

"A estratégia sócio-econômica é um mix de objetivos econômicos e de objetivos sociais parcialmente compativeis e parcialmente incompatíveis de uma coalisão real ou potencial de atores conduzida por um estrategista.

...uma classificação bem simples das estratégias em duas categorias: as estratégias motrizes e as estratégias derivadas. As estratégias motrizes são, em geral, autônomas; fundam-se em projetos de longo prazo definidos com uma boa precisão dos objetivos fundamentais. Têm um efeito de tracionar a estratégia dos outros atores, pois conformam a estrutura do ambiente. Esta conformação é devida ao potencial de energia que elas portam: as coordenadas comerciais (conjunto produto-mercado), as dotações financeiras $e$, sobretudo, a organização, conjunto (estruturas-comportamentos internos) fundamentado sobre a qualidade dos recursos humanos, isto é, sobre suas qualificações, sobre as condições de vida no trabalho, sobre 0 consenso traduzido pelo 'contrato de atividade periodicamente negociável'. Os custos ocultos são uma medida aproximada das reservas de energia liberáveis, sob condição, graças a um investimento em recursos humanos.

...As estratégias derivadas, ou induzidas, resultam de um efeito de derivação (emulação ou simples imitação) das estratégias motrizes. No limite, elas podem se constituir em pseudo-estratégias, tendo em vista seu atraso face às estratégias ativas eficazes ou à sua grande inércia proveniente de um contrato de atividades excessivamente conflituoso ou por uma ausência de pilotagem causada pela incerteza e pela renúncia à estratégia ativa.

... As estratégias motrizes implantam-se através de alianças (freqüentemente implícitas) com os parceiros ativos e com os parceiros passivos (princípio do 'portfolio' de conveniências)" 28 .

A operacionalização e o desenvolvimento de uma verdadeira estratégia sócio-econômica integrada da empresa necessitam de quatro inovações no seu funcionamento corrente: um novo estilo de relações sociais, uma nova concepção do sistema de informação e de comunicação, assim como da organização do trabalho e, enfim, uma certa evolução cultural marcada pela renúncia às alternativas ficticiamente maximizadoras ${ }^{29}$.

Os objetivos estratégicos são também inseridos no painel de pilotagem sócio-econômica, de forma a operacionalizar a estratégia da empresa ${ }^{30}$.

O método sócio-econômico procura sempre desenvolver procedimentos heurísticos. Um procedimento heurístico é um procedimento onde os algoritmos são mais simples e utilizados de um modo mais freqüente. De forma operatória, um procedimento heurístico repousa sobretudo em uma multiplicação de captores de informação sobre o ambiente externo e interno, em uma multiplicação dos espaços de reflexão estratégica, em uma multiplicação dos pontos de controle estratégico.

As proposições de operacionalização de uma estratégia sócio- econômica podem ser resumidas da forma seguinte:

- O contrato de atividades periodicamente negociável, fator de estabilização do comportamento do pessoal.

- A preferência por um sistema de informação mais completo e mais transparente.

- A preferência por modelos de gestão não maximizadores.

- A preferência por procedimentos mais flexíveis, que favoreçam a descoberta das soluções possíveis (heurísticos).

\section{RESULTADOS DA APLICACÃO DO MÉTODO DE INTERVENCÃO SÓCIO-ECONÓMICA NAS EMPRESAS E MAS ORGANIZAÇÕES}

O método de análise sócio-econômico foi aplicado até o momento em mais de cem organizações de todo tipo e tamanho (de 20 a 4500 pessoas), em vários setores econômicos (indústria, serviços públicos, hospitais, bancos, escritórios de consultoria), e em situações econômico-financeiras favoráveis ou não, principalmente na França mas também em outros países, com cerca de 200.000 horas de intervenção-pesquisa acumuladas nos últimos quinze anos.

As soluções experimentadas são variáveis de uma empresa a outra, de acordo com as principais disfunções, com o setor de ativi-
26. Ver ISEOR. Présentation de l'approche socio-économique. Documento de divulgaçāo, s.d., 5 págs.

27. Ver SAVALL, H. \& MARTINET, A. "Les axes de la mise en oeuvre de la stratégie projective ouverte". Op. cit.

28. Ver SAVALL, H. Reconstruire l' entreprise. Analyse socio- économique des conditions de travail. Op. cit.

29. Ver SAVALL, H. \& MARTINET, A. "Stratégie socioéconomique de l'entreprise". Op. cit.

30. Ver SAVALL, H. Reconstruire I' entreprise. Analyse socio- économique des conditions de travail. Op. cit. 
dade etc. Todas as soluções apresentam, entretanto, uma característica comum: são soluções globais comportando modificações nas seis áreas básicas de disfunção supra citadas.

Além disso, essas soluções comportam a operacionalização de sistemas de gestão permanente, a fim de que a empresa ou organização disponha de um sistema de pilotagem de seus custos ocultos e de sua performance sócio-econômica, sem o qual o nível de custos ocultos voltaria a crescer ao fim de pouco tempo ${ }^{31}$.

A média de custos ocultos encontrados nas intervenções sócio- econômicas já realizadas é de 12.000 dólares por pessoa e por ano. As intervenções realizadas mostram que, do total de custos ocultos, cerca de 30 a 50 por cento podem ser reduzidos; o restante dos custos, inerentes à vida da organização, são considerados como fisiológicos ${ }^{32}$.

\section{A PERTINÊNCIA DO ENFOQUE SÓCIO-ECONÔMICO À REALIDADE DA ADIMINISTRAÇÃO DE EMPRESAS NO BRASIL.}

Do ponto de vista da introdução no Brasil da intervenção-pesquisa, é necessário reconhecer que a tradição de pesquisa em Ciências da Administração tem sido sobretudo de importação acrítica de modelos conceituais anglo-saxões e, mais recentemente, japoneses, e de fuga da análise teórica dos fenômenos concretos de gestão das empresas brasileiras.

Na realidade, a distância entre a pesquisa em Ciências da Administração e os fenômenos concretos da vida social e econômica das empresas brasileiras tem raízes profundas.

Tem raízes nas empresas que, historicamente, não viram necessidade da pesquisa para resolver seus problemas, e nas universidades e instituições de ensino e pesquisa, que sempre acreditaram poder analisar as empresas sem sujar muito as mãos.

Uma análise em busca da essência dos problemas da administração, ao mesmo tempo que oportuna, deverá enfrentar, inevitavelmente, esta inércia histórica das estruturas mentais.

Os problemas específicos da administração poderão, entretanto, muito se beneficiar de uma análise flexível que parte das disfunções existentes para a busca de soluções adaptadas, utilizando uma metodologia de pesquisa que se apóia nos atores da empresa, e uma matriz de análise conceitual, baseada na estrutura da organização e no comportamen- to dos agentes.

Vai ser necessário certamente um árduo trabalho de experimentação para identificar os fatores específicos mais ou menos importantes para o conhecimento e explicação dos problemas de funcionamento das empresas no Brasil. Por exemplo, a importância da relação custos ocultos-custos visíveis, as questões de participação e de poder, o peso dos diferentes fatores estruturais e comportamentais na determinação da performance.

Entretanto, o conjunto de trabalhos de pesquisa já realizado na França pelo ISEOR, ao mesmo tempo que as suas concepções teóricas e as ferramentas operacionais de gestão, poderão ser utilizados como ponto de partida indispensável para um desenvolvimento intenso e rápido desse tipo de análise no Brasil, mais, ainda, ao se levar em conta que as semelhanças culturais e do ponto de vista de clima social são muito maiores entre esses dois países do que entre a realidade sócio-cultural brasileira e a anglo-saxã ou japonesa.

As perspectivas favoráveis a uma aplicação do enfoque sócio-econômico no Brasil parecem ser, portanto, bastante pertinentes, tendose em conta as seguintes considerações:

- A pesquisa de um desenvolvimento eclético que se apóie em modelos heurísticos parece ser adequada ao ambiente social e econômico brasileiro, que se apresenta como incerto e sujeito a profundas alterações de percurso a curto e médio prazos.

- A pertinência, com relação a um país em desenvolvimento, da estratégia de partir do potencial da empresa e desenvolver as opções estratégicas (nos níveis de produtos, mercado e ambiente concorrencial) com eixo no desenvolvimento do potencial humano e avaliando os resultados econômicos, tanto do ponto de vista imediato, como do ponto de vista da criação de potencial futuro.

- A pesquisa-intervenção parece ser uma metodologia adequada para a pesquisa de disfunções específicas das empresas em um meio sócio-cultural específico e para auxiliálas a aperfeiçoar seu potencial de contribuição ao desenvolvimento econômico e social do país.

- As ferramentas de gestão - contrato de atividades periodicamente negociável, painel de pilotagem sócio-econômica, matriz de competências, matriz de auto-análise da gestão do tempo e plano de ações prioritárias - foram conceitualmente bem desenvolvidas e experimentalmente bem testadas na França, podendo, portanto, ser rapida e eficazmente adaptadas e integradas às ferramentas de gestão das empresas brasileiras ${ }^{33}$. 